\title{
Green synthesis of silver nanoparticles by Adhatoda vasica $\mathrm{L}$.
}

Bushra Bibi ${ }^{1}$, Arifa Tahir ${ }^{2}$, Mubbara Arshad ${ }^{2}$, Saira Khan ${ }^{3}$, Faiza Anum $^{3}$, Fareeha Bashir ${ }^{4}$ and Shahid Raza ${ }^{5 *}$

1. Department of Chemistry, Lahore College for Women University, Lahore-Pakistan

2. Department of Environmental Science, Lahore College for Women University, Lahore-Pakistan

3. Department of ORIC, Lahore Garrison University, Lahore-Pakistan

4. University Institute of Medical Lab Technology, University of Lahore-Pakistan

5. Department of Biotechnology, University of central Punjab, Lahore-Pakistan

*Corresponding author's email: dr.raza03@gmail.com

Citation

Bushra Bibi, Arifa Tahir, Mubbara Arshad, Saira Khan, Faiza Anum, Fareeha Bashir and Shahid Raza. Green synthesis of silver nanoparticles by Adhatoda vasica L. Pure and Applied Biology. Vol. 9, Issue 4, pp2415-2424. http://dx.doi.org/10.19045/bspab.2020.90256

\begin{tabular}{llll}
\hline \hline Received: 02/03/2020 & Revised: 30/05/2020 & Accepted: 22/07/2020 & Online First: 24/07/2020 \\
\hline \hline
\end{tabular}

\section{Abstract}

Biological approaches have essential part in Nanotechnological field. Green methods are expected to minimize environmental problems. Silver nanoparticles manufactured by means of Adhatoda Vasica $L$ leaf extract. Ag ions decline as well as formation of Silver nanoparticles (AgNPs) were gauged by Ultra violet- vis (UV-Vis) spectroscopy, Fourier transform infrared spectroscopy (FTIR) as well as Xray powder diffraction (XRD) studies showed crystalline nature of silver NPs with dimension series from twenty nanometer to fifty nanometers. The UV/Vis spectrophotometry reveals the capping action of Adhatoda Vasica L. and the color change after the reaction has proceeds among AgNO3 and Adhatoda Vasica L. leaf extract. The FTIR identify the capping ability of Adhatoda Vasica L. that may liable for decline of $\mathrm{Ag}+$ as well as stability of $\mathrm{Ag}$ nanoparticles. Currently, ejection of harmful colorants over fabric industries in $\mathrm{H}_{2} \mathrm{O}$ bodies similar to lakes, rivers as well as groundwater has converted to severe case, which imparts to rise in pollution intensities considerably. The wastewater having heavy metals also becomes an alarming factor now-a-day. The fungal infections spreading day by day and the algal blooms also polluting the environment as well as the oxidative substances are also more harmful to the environment. In the present study we investigated green-synthesized usage Ag nanostructured particles for dyes destruction e.g. methylene blue and methylene green. It was found that the AgNPs has great potential to heavy metals deletion like cadmium as well as zinc. They showed antioxidant property against 2,2-diphenyl-1-picrylhydrazyl (DPPH). The AgNPs significantly inhibit the fungal growth (Aspergilus specie LC.33) and algal growth (Chlorella vulgularis). It is concluded from the study that biogenic AgNPs have many environmental applications. Adhatoda Vasica L. leaf extract could commercially utilize as Silver (Ag) nanoparticles (Green Synthesis).

Keywords: Adhatoda vasica L.; AgNPs; Aspergilus sp. LC33; Chlorella Vulgularis; DPP; Heavymetals; Methylene blue and Methylene green

\section{Introduction}

The nanotechnology has given a wide research as of late by meeting with the assorted field of science and making sway on all types of life [1]. In late time, nanotechnology is assuming a fundamental job in the examination of material science because of its particular qualities, for 
example, morphology, size, shape and conveyance [2, 3] Metallic nanoparticles having inventive applications and crystalline nanoparticles are utilized as antimicrobial, antibacterial and anticancer operators just as biomolecular discovery, diagnostics and therapeutics [4-7].

Various plants and their concentrates are utilized for the generation of nanoparticles are progressively advantageous when contrasted with other characteristic strategies that incorporate the appallingly propelled proportions of bacterial societies [8-10]. The focal point of the present work is to apply green science approaches in the blend of silver nanoparticles (AgNPs) utilizing fluid leaf concentrates of Adhatoda Vasica L.as decreasing and topping operators. Adhatoda Vasica L. is a significant therapeutic plant has a place with the family Acanthaceae. The plant parts are accounted for to be expectorant, abortifacient, antimicrobials, antitussive and anticancer. A few mixes had been detached from this plant to treat malignancy. The present examination focused on the green union of AgNPs from the leaves of A. Vasica L. furthermore, the portrayal of the so framed nanoparticles with $\mathrm{X}$-beam diffraction (XRD), Fourier change infrared (FTIR) and bright unmistakable (UV-Vis) spectroscopy [11].

Colors are a significant class of engineered natural mixes utilized in assortment of utilizations [12]. The arrival of color effluents in amphibian frameworks is major natural concern since tinge not just abatements daylight infiltration and broke up oxygen in water bodies, yet additionally discharges dangerous mixes during substance or organic response pathway that influences oceanic greenery. Reductive corruption of risky colors with metal nanomaterials is a helpful debasement process in view of their one of a kind physiochemical and electronic properties which are absent in mass materials [13-15]. In this manner, it is expected that higher cancer prevention agent action of nanoparticles is may be because of the special adsorption of the cell reinforcement material from the concentrate onto the outside of the nanoparticles. Various parameters like surface region, molecule size and surface reactivity decide the lethality of the nanoparticles in plant separates [16]. Antifungal movement of AgNPs was resolved utilizing Agar-well dispersion technique. Potato dextrose agar (PDA) plates were readied, and afterward the medium was kept for disinfection and, a great many hardenings parasitic societies were swabbed on these plates. Wells of $5 \mathrm{~mm}$ distance across were made on PDA plates utilizing a stopper borer and fifty microliter of nanoparticles arrangement was estimated [17]. Green growth is a significant part of our condition and biological system. Their significant advantages incorporate uses as biofertilizer, biofuel, contamination control operator (green growth bioreactors), stabilizer of casein and wellspring of sustenance (B complex nutrients and minerals) [18]. Our methodology is novel because of the way that we planned to look at over all the organic execution of silver colloids got by thoroughly green concoction decrease techniques utilizing A-Vasica extricates. The green-combined AgNPs were described, and in the edge of extensive screening [19]. The nano estimated metal oxides are named the promising ones for substantial metals expulsion from watery frameworks This is a direct result of their enormous surface zones and high exercises brought about by the size quantization impact [20].

\section{Materials and methods Plant and synthetic substances}

The plant Adhatoda Vasica L. was gathered from the neighborhood (Soon Valley, Pakistan). Silver nitrate, methylene blue and methylene green. DPPH, ascorbic corrosive and methanol. Zinc sulfate and Cadmium 
nitrate tetrahydrite. Aspergillus specie LC33 and BG11 stock arrangement.

Adhatoda Vasica L. remove arrangement Fluid concentrate of plant Adhatoda Vasica L. was made by taking $10 \mathrm{~g}$ of plant material (powder) in a cone shaped cup of thousand milliliter alongside four hundred milliliter refined water and carry it to bubble for twenty minutes to thirty minutes. At that point the readied arrangement was passed however the Whatman's channel paper and concentrate was gathered as a filtrate in another flagon and put away for additional utilization in tapered jar and coved by aluminum foil to ensure the passage of any polluting influence in the concentrate so that, it very well may be utilized consistently.

\section{Amalgamation of nanoparticles}

For the amalgamation of Silver nanoparticles, arrangement of $\mathrm{AgNO} 3$ (two millimolar) was set up in hundered milliliter twofold refined water. The water concentrates of Adhatoda Vasica L. (twenty milliliter) was blended with hundred milliliters of AgNO3 arrangement in a two hundred fifty milliliter of cone shaped cup. At that point the jar was set in the shaker at sixty-degree Celsius temperature for five hours for the total blending of salt arrangement and plant extricate. That was showing by the adjustment in the shade of arrangement from light to dim which demonstrate the development of nanoparticles.

\section{Portrayal}

Bright unmistakable ghastly examination was performed for all examples furthermore, the retention maxima were recorded at a wavelength of two hundred to eleven hundred nanometer utilizing UV/Visible Hitachi spectrophotometer (model UV2800). X-Ray diffraction investigation of the readied silver nanoparticles was done on XRD [D8-Discover (Germany)].

Fourier Transform Infrared Spectroscopy
(FTIR) was utilized to identify the conceivable useful gatherings of biomolecules present in the plant remove for this reason dry powders of the concentrate and nanoparticles arrangements were dissected by Midac MC two thousand Spectrometer inside range five hundred to thirty-five hundred.

\section{Utilizations of AgNPs}

\section{Color evacuation action}

For the color evacuation action of green orchestrated nanoparticles, the color methylene blue and methylene green was utilized. Ten ppm of color arrangement was made. At that point two milligram of green integrated nanoparticles were included ten milliliters of arrangement from each color independently in hundred milliliter cone shaped carafes. The cups were kept on the water shower for thirty minutes at seventydegree Celsius temperature. The productivity of green integrated nanoparticles for color expulsion was likewise considered with ultra violet-Vis spectrophotometer.

\section{Substantial metal expulsion movement}

For the expulsion of substantial metal from water overwhelming metal evacuation zinc sulphite 7-hydrate and cadmium nitrate tetrahydrite was utilized. For this reason, the stock arrangement of two hundred ppm of the two salts was arranged separately in five hundred milliliter of funnel shaped cups with refined water. At that point further weakening of fifty ppm, hundred ppm as well as one hundred fifty ppm were set up with refined water separately for each salt. At that point $1 \mathrm{mg}$ of silver nanoparticles was included every weakening of each salt to check the evacuation of zinc and cadmium substantial metals from water. At that point every one of the weakening with nanoparticles were kept in water bath for twenty to thirty minutes at seventy degree Celsius under shaking condition. For the affirmation of zinc and cadmium overwhelming metal expulsion from the 
water, every weakening of fifty ppm, hundred ppm as well as one hundred fifty ppm was investigated in nuclear ingestion spectrophotometer after filtration of every weakening by Whatman's channel paper.

Cancer prevention agent capability of green combined AgNPs

For the free radical rummaging action of the orchestrated nanoparticles of silver was dictated by utilizing DPPH strategy. DPPH arrangement of $0.1 \mathrm{mM}$ was set up in $95 \%$ methanol and $1 \mathrm{ml}$ of this arrangement was added to $3.0 \mathrm{ml}$ of incorporated nanoparticles arrangement (10-80 ug ml). $0.00018 \mathrm{~g}$ $(0.0006 * 3$ which is equivalent $60 \mathrm{ug}$ of each nanoparticle which is equivalent to the $60 \mathrm{ug} \backslash 3 \mathrm{ml}$ of each nanoparticle) arranged by refined water. Presently every blend was brooded for $30 \mathrm{~min}$ at dull conditions at room temperature. After $30 \mathrm{~min}$ the decrease in absorbance at $517 \mathrm{~nm}$ was estimated at 517 $\mathrm{nm}$ utilizing an ultra violet- $\mathrm{V}$ is spectrophotometer. Ascorbic corrosive was utilized as a standard.

Antifungal action of green blended AgNPs $5 \mathrm{~g}$ of potato dextrose (PD) was included in hundred milliliter twofold refined water in two fifty milliliter measuring glass and shake well. five plates of petri dish were readied arrangement of potato dextrose (PD). Tomato growth was included each plate with the assistance of vaccination on the Bunsen burner gave heat medium in Laminar Air Flow Cabinet (J-IEP). At that point one milligram of AgNPs was included each plate independently under the laminar stream with cleaned vaccinating needle. At that point all the petri dishes were kept in the hatchery at twenty-five degree Celsius for three days. Check the most extreme number of antifungals following three days the development of parasite on each plate was analyzed cautiously by utilizing particular amplifying glass. Likewise ascertain the contagious restraint zone so as to assess the antifungal viability of nanoparticles against pathogens.

Hostile to algal movement of green orchestrated AgNPs

$1000 \mathrm{ml}$ arrangement was made in volumetric jar (1000 ml) by including BG eleven stock one (ten milliliter), stock two (ten milliliter), stock three (ten milliliters), stock five (one milliliter), NaNO3 1.5 g plus Na2CO3 $0.02 \mathrm{~g}$ Then this arrangement was convert into two tapered jar (thousand milliliter) five foundered milliliter in each. At that point both the flagons were secured with cotton and autoclaved for four to five hours with temperature of one twenty-degree Celsius. At the point when the temperature drops to fifty degree take jars were expelled from autoclave when the temperature drops to fifty degree Celsius. At that point these cups for were kept at room temperature for twentyfour hours. Crisply developed green growth were rotator in four hawk tubes (fifty milliliter) at three thousand rotation per minute. The supernant was squandered and green growth were gathered into one cylinder and again rotator it. After centrifugation the green growth was weighed subsequent to drying. The green growth was changing over similarly into two cone shaped carafes containing arrangement. One carafe was kept for control and $0.009 \mathrm{~g}$ nanoparticles were included into the other jar. At that point both of the carafes were given air circulation and light for the best possible development for 24 hours.

\section{Results and discussion}

\section{UV- visible spectrum studies}

UV-Vis. spectroscopy estimation demonstrated that the SPR absorbance band of Ag nanoparticles arranged by Adhatoda vasica L. leaf extricate focused at 40 four hundred to five hundred nanometer just as step by step floods in power with the ascent in response time. Recurrence just as width of the surface plasma assimilation top relies upon the size just as state of the metal- 
nanoparticles in addition to on the dielectric consistent of the metal itself and the neighboring medium. UV-Vis spectra show the pinnacles roughly at $418,424,430$ and $442 \mathrm{~nm}$ obviously demonstrating the arrangement of AgNPs in Adhatoda Vasica L. By plotting UV-Vis retention of the response blend against time, time course of the response was gotten. The bend shows expanded absorbance in different time interims $(1,3,7$, and $12 \mathrm{hrs})$ and the pinnacles were seen at $424 \mathrm{~nm}$ relating to the surface plasmon reverberation of AgNPs. The perception showed that during the response time frame, an expansion in absorbance was seen in this wavelength, which can be because of the increment underway of colloidal AgNPs (Fig. 1).

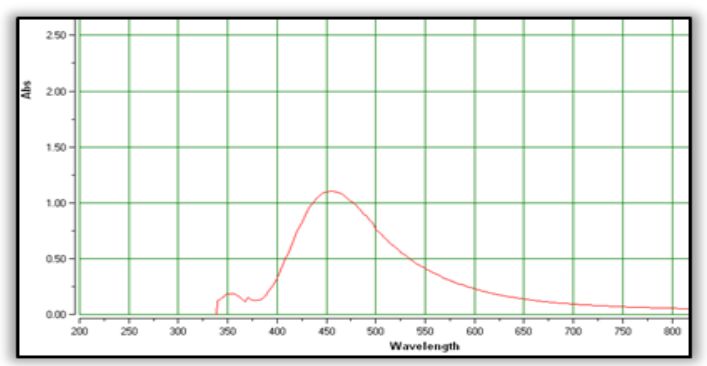

Figure 1. UV-Vis spectra of AgNPs along with Adhatoda Vasica L. leaf extract

\section{XRD investigation}

A common XRD example of AgNPs combined at ten min of hatching period was found to have face cubic focused structure. (Fig. 2) shows the XRD example of the dried nanoparticles and proposes that the orchestrated AgNPs are crystalline in nature. The diffraction tops saw in the 20 territory at $00-600$ is 32.06 as well as 38.64 can be filed to the (32) and (48) directions individually, affirmed that the combined silver nanoparticles are made out of unadulterated crystalline silver. The XRD designs showed here are predictable with prior reports [21]. The normal crystalline size is determined utilizing Debye-Scherrer recipe,

$\mathrm{D}=\mathrm{k} \lambda / \beta \cos \theta$

Where $\mathrm{D}$ is the normal crystalline size of the nanoparticles, $\mathrm{k}$ is geometric factor $(0.9), \lambda$ is the wavelength of $\mathrm{X}$-beam radiation source and $\beta$ is the rakish FWHM (full-width at half limit) of the XRD top at the diffraction edge $\theta$ [22]. The determined normal crystalline size of the AgNPs is $22 \mathrm{~nm}$.

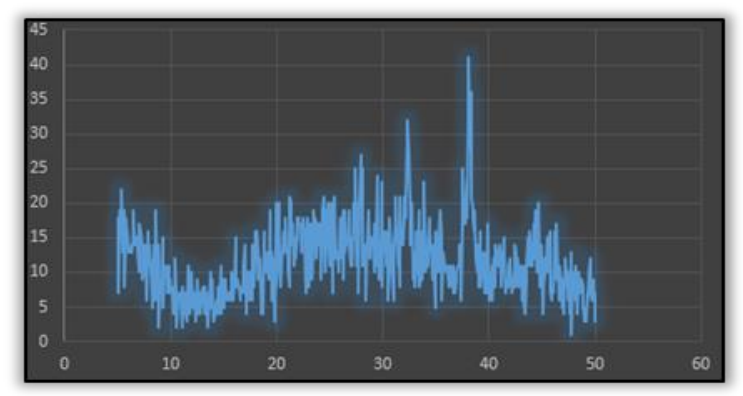

Figure 2. XRD image of AgNPs green synthesized by Adhatoda Vasica L.

FTIR analysis

FTIR examination was used for the portrayal of the biomolecules present in the plant remove which are responsible for the generation of nanoparticles. FTIR gives the data about useful gatherings present in the 
incorporated AgNPs for understanding their change from basic inorganic AgNO3 to essential silver by the activity of the various phytochemicals which would act at the same time as decreasing, balancing out and topping specialist. (Fig. 3) shows FTIR tops were seen at $3726.47 / \mathrm{cm}$ shows $\mathrm{O}-\mathrm{H}$ extending vibration of the hydroxyl gathering [23], $\mathrm{H}-$ fortified alcohols, phenols or N-H extending of I and II amines and amides. The top at $2360.87 / \mathrm{cm}$ compares to $\mathrm{C}-\mathrm{H}$ stretch alkanes and $\mathrm{O}-\mathrm{H}$ carboxylic acids [24]. The top at
$1597.16 / \mathrm{cm}$ add to $\mathrm{C}=0$ stretch $\alpha, \beta$ unsaturated aldehydes and ketones, the top at $1315.49 / \mathrm{cm}$ appointed to $\mathrm{O}-\mathrm{H}$ twist demonstrates carboxylate. The band at $1072.42 / \mathrm{cm}$ demonstrates the nearness of C$\mathrm{N}$ stretch aliphatic amines, the top at $601.7 / \mathrm{cm}$ was doled out for $\mathrm{C}-\mathrm{Cl}$ extending vibrations of alkyl halides. The useful biomolecules are carboxylic and amine bunches engaged with the decrease of silver particles, as affirmed by FTIR range.

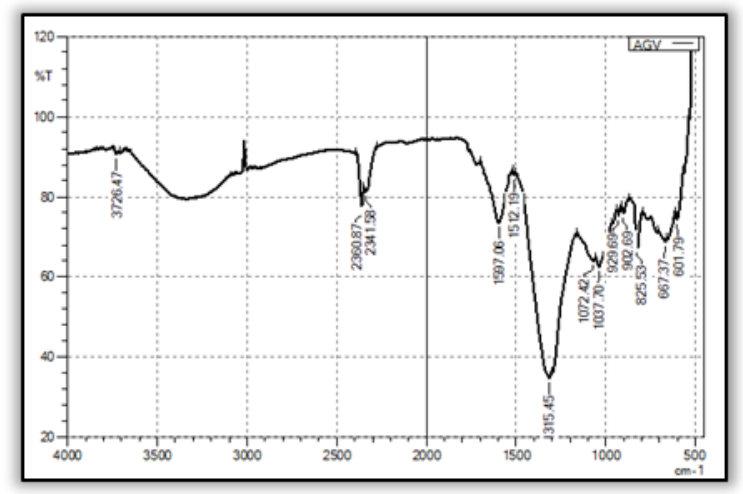

Figure 3. FTIR spectrum of green synthesized AgNPs

\section{Applications}

\section{Catalytic degradation of Methylene blue and methylene green dye}

So as to research the synergist action of AgNPs, decrease of methylene blue (water contaminant) was conveyed utilizing green blended AgNPs in shake cups. The impact of time and temperature was examined. The degree of corruption of Methylene blue utilizing AgNPs as impetus was checked by UV-unmistakable

spectrophotometer (Thermo electron 300). The retention tops were seen at $652 \mathrm{~nm}$ and $619 \mathrm{~nm}$ of methylene blue and methylene green separately [25].

\section{Impact of temperature}

The information of (Fig. 4) shows the impact of temperature $\left(40^{\circ} \mathrm{C}, 50^{\circ} \mathrm{C}, 60^{\circ} \mathrm{C}\right.$ and $\left.70^{\circ} \mathrm{C}\right)$ on decolorization of methylene blue and methylene green colors. It was discovered that decolorization increments with increment in temperature, greatest decolorization of methylene green $(100 \%)$ was seen at $70^{\circ} \mathrm{C}$. the decolorization of methylene blue at $40^{\circ} \mathrm{C}, 50^{\circ} \mathrm{C}, 60^{\circ} \mathrm{C}$ and $70^{\circ} \mathrm{C}$ was $80 \%$ individually.

\section{Effect of time}

The information of (Fig. 5) shows the impact of time (10 minutes, 20 minutes, 25 minutes and 30 minutes) on the decolorization of methylene green and methylene blue colors. It was discovered that decolorization increments with the expansion in time; greatest decolorization of methylene green $(100 \%)$ was seen at 30 minutes. The decolorization of methylene blue at 10 minutes, 20 minutes, 25 minutes and 30 minutes was $80 \%$ individually. 


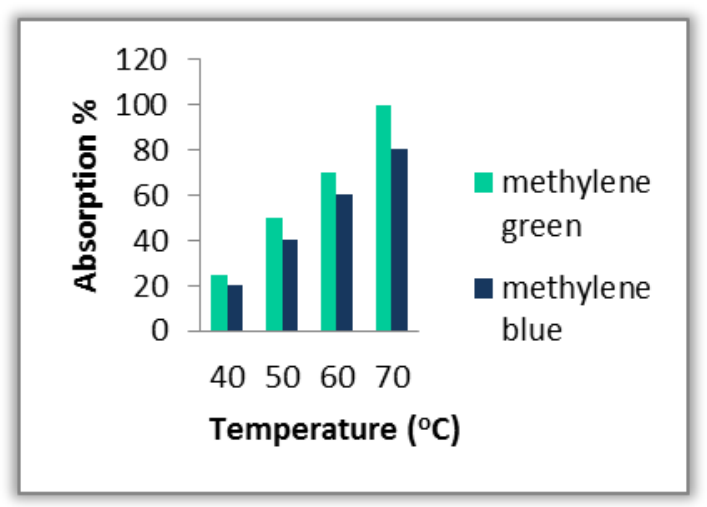

Figure 4. Effect of temperature on the removal of methylene blue and methylene green

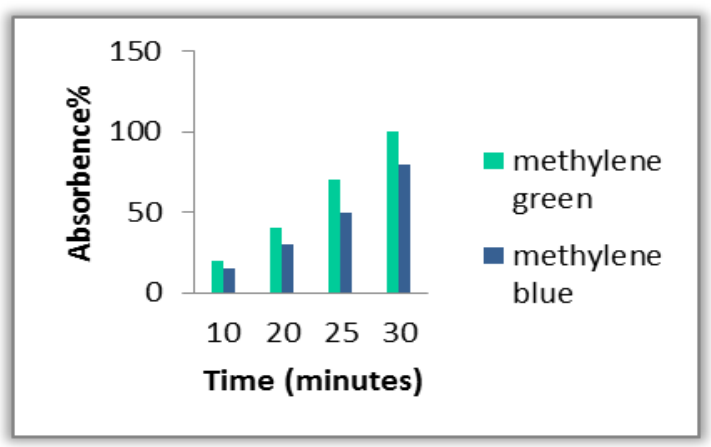

Figure 5. Effect of time on the removal of methylene blue and methylene green

Removal or heavy metal (Cadmium and Zinc) by AgNPs

Expulsion effectiveness of cadmium and zinc from water was dissected with AgNPs. The impact of AgNPs on the evacuation of $\mathrm{Cd}$ and $\mathrm{Zn}$ was checked by Absorption spectrophotometer (examination mode: fire/manual). Impact of groupings of $\mathrm{Cd}$ and zinc was seen on the expulsion proficiency of AgNPs. It was seen that Maximum expulsion of cadmium was acquired at any rate evacuation at $150 \mathrm{ppm}$. What's more, greatest evacuation of zinc was gotten at any rate expulsion at $150 \mathrm{ppm}$. With the expansion in the convergence of cadmium and zinc, the expulsion effectiveness of AgNPs was diminished.

Antioxidant potential of green synthesized AgNPs

Antioxidant activity of the Silver nanoparticles was assessed by DPPH, which displayed a profound purple shading with a most extreme absorbance at $517 \mathrm{~nm}$. Antioxidant potential (\%) of AgNPs was surveyed by DPPH arrangement $(0.1 \mathrm{Mm}$ in 95\% methanol), utilizing ascorbic corrosive as positive control. The absorbance perusing at different time interims, for 10min, 20min, and 30min was taken by UV-VIS spectrophotometer (ANSI IEE STD 7541985). The purple arrangement containing DPPH arrangement goes yellow to light yellow shading after the expansion of DPPH arrangement, which shows the rummaging of free radicals and nearness of cancer prevention agent movement [26]. The mean rate restraint estimations of combined AgNPs were $8.88 \%, 8.83 \%$, and $8.80 \%$. A continuous lessening in the cancer prevention agent capability of AgNPs was seen as the presentation time expanded. Most extreme 
cancer prevention agent potential $(8.88 \%)$ was seen at any rate time $10 \mathrm{~min}$.

Antifungal activity of green synthesized AgNPs

Antifungal action of Silver nanoparticles was emerging as an opponent of Aspergilus specie LC 33. Potato Dextrose Agar was provided with $0.001 \mathrm{mg}$ of AgNPs. Aspergilus specie LC 33 was vaccinated at agar plate of $8 \mathrm{~cm}$ distance across. Petri plates was brooded at $27 \mathrm{oC}$ for 14 days. The development of parasite was checked after at regular intervals as (Fig. 6(a) shows the development of Aspergilus specie LC 33on control Petri plate and (Fig. 6(b) shows the development of control Petri plate following 14 days and (Fig. 6(c \& d) shows the impact of AgNPs on Aspergilus species LC 33 when incubated.

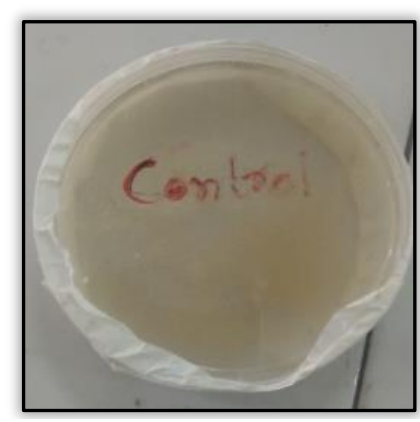

A

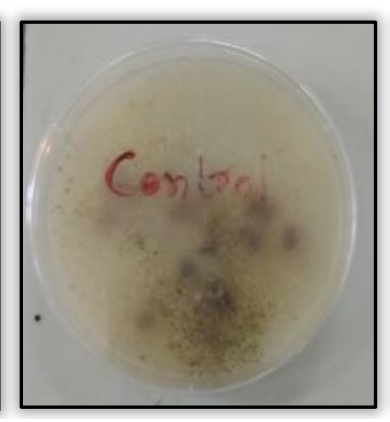

b

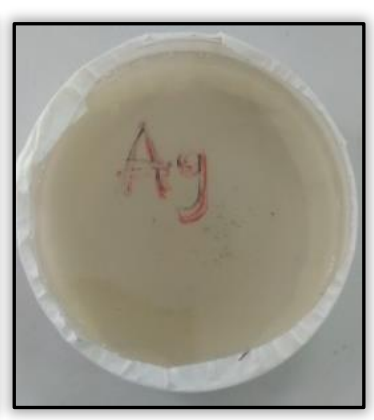

c

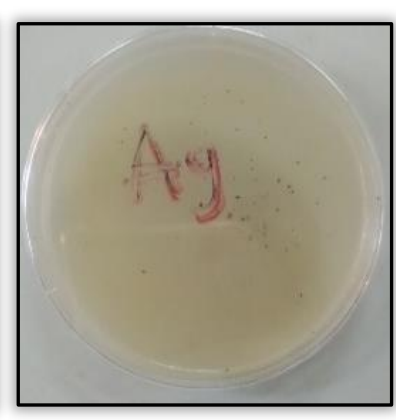

d

Figure 6. Shows the control petri plate before (a) and after (b) incubation and AgNPs Petri plate before (c) and after (d) incubation

Anti-algal activity of green synthesized AgNPs

The green synthesized silver nanoparticles exhibited the anti-algal activity. Effect of AgNPs on pigment content as a measure of algal growth was investigated. The data of (Fig. 7) shows the effect of AgNPs on the growth of chlorella vulgaris var. in shake flasks. The experiment was conducted for 15 days. It was observed that AgNPs significantly reduced the growth of chlorella vulgaris var. the biomass was $0.02 \mathrm{~g} / \mathrm{ml}$. after 15 days of aeration the biomass was reduced to $0.0008 \mathrm{~g}$. The biomass concentration after $3,6,9,12$ and 15 days was $0.0096 \mathrm{~g}, 0.008 \mathrm{~g}$, $0.006 \mathrm{~g}, 0.005 \mathrm{~g}$ and $0.004 \mathrm{~g}$ respectively. The (Fig. 8) shows the visible reduced biomass of chlorella vulgaris var. as compared to the control media show the higher biomass.

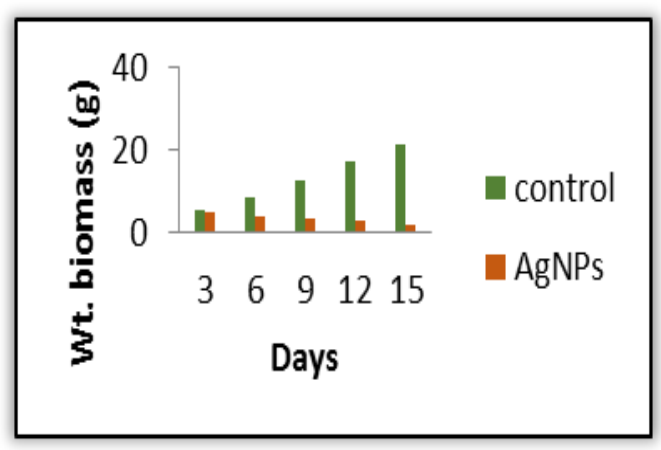

Figure 7. Effect of AgNPs on the biomass of chlorella vulgularis var. as compared to the control biomass 


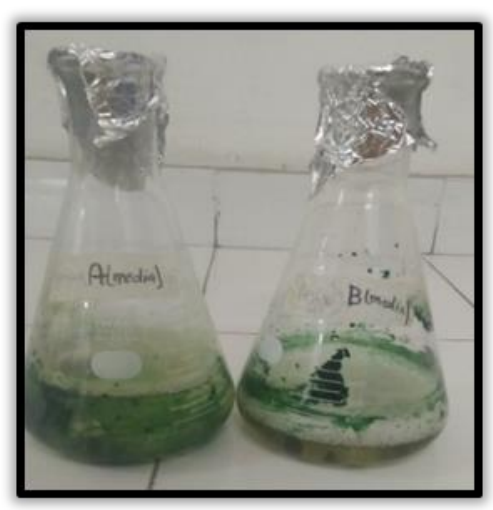

Figure 8. Effect of AgNPs on the growth of Chlorella vulgularis var. after aeration as compared to control growth

\section{Conclusion}

It is concluded from the study that biogenic AgNPs have many environmental applications. Therefore Adhatoda Vasica $L$. leaf extract can be commercially utilize for Green Synthesis of Silver (Ag) nanoparticles. Authors' contributions

Conceived and designed the experiments: B Bibi, A Tahir \& F Anum, Performed the experiments: M Arshad \& B Bibi, Analyzed the data: S Khan \& S Raza, Contributed materials/ analysis/ tools: F Bashir, Wrote the paper: B Bibi, F Anum \& S Khan.

\section{References}

1. Baker S \& Satish S (2012). Endophytes: toward a vision in synthesis of nanoparticle for future therapeutic agent. Inter J Bio-Inorg Hybd Nanomat 1(2): 6777.

2. Andres RP, Datta S, Janes DB, Kubaik CP, Reifemberger R \& Naiwa HS (2000). Handbook of Nanostructured Material and Nanotechnol, HS Nalwaed 4: 179231.

3. Murphy CJ (2008). Sustainability as an emerging design criterion in nanoparticle synthesis and applications. $J$ of Material Chem 19.

4. Rai M, Yadav A. \& Gade A (2009). Silver nanoparticles as a new generation of antimicrobials. Biotechnol. Adv 27(1): 7683.
5. Elechiguerra JL, Burt JL, Morones JR, Camacho-Bragado A, Gao X, Lara HH \& Yacaman MJ (2005). Interaction of silver nanoparticles with HIV-1. Nanobiotechnol 3(1): 6.

6. Crooks RM, Lemon B, Sun L, Yeung LK \& Zhao M (2001). DendrimerEncapsulated Metal Nanoparticles: Synthesis, Characterization, and Applications to Catalysis. Top Curr Chem 212(3): 82-135.

7. Gittins DA, Bethell D, Nichols RJ \& Schiffrin DJ (2000). Diode-like electron transfer across nanostructured films containing a redox ligand. $J$ of Matererial Chem 10: 79-83.

8. Parashar, Kumar U, Saxena, Preeti S \& Srivastava (2009). Bioinspired synthesis of silver nanoparticles. Digest $J$ of Nanomaterials \& Biostructures 4(1): 159166.

9. Najitha BA, Balasubramanian C \& Vinayaga MP (2014) Biosynthesis of silver nanoparticles using Bacillus thuringiensisagainst dengue vector, Aedes aegypti (Diptera: Culicidae). Parasitol Res 113: 311-316

10. Sastry M, Ahmed A, Khan MI \& Kumar R (2003). Biosynthesis of metal nanoparticles using fungi and actinomycete. Material chemistry division, 85(2).

11. Bhumi G, Rao ML \& Savithramma N (2015). Green synthesis of Silver 
Nanoparticles from the leaf extract of Adhatoda Vasica Nees and Assessment of its Antibacterial Activity. Asian $J$ of Pharma and Clin Res 8(3): 62-67

12. Habibi MH \& Askari E (2011). Photocatalytic degradation of an azo textile dye with manganese-doped $\mathrm{ZnO}$ nanoparticles coated on glass. Iranian J of Catalysis 1: 41-44.

13. Kim JS, Kuk E, Yu KN, Kim JH, Park SJ, Lee HJ, Kim SH, Park YK, Park YH, Huwang Y, Kim YK, Lee YS, Jeong DH \& Cho MH (2007). Antimicrobial effects of silver nanoparticles, Nanomed Nanotehnol Biol Med 3: 95-101.

14. Amini MHN \& Farnia SMF (2014). Green synthesis of silver nanoparticles supported on cellulose and their catalytic application in the scavenging of organic dyes. New J Chem 38: 1581-1586

15. Bhakya S, Muthukrishnan S, Sukumaran M \& Muthukumar M (2015). Biogenic synthesis of silver nanoparticles and their antioxidant and antibacterial activity. Appl Nano Sci 6(5): 755-766.

16. Jacob SH, Finub JS \& Narayanan A (2012). Synthesis of silver nanoparticles using Piper longum leaf extracts and its cytotoxic activity against Hep-2 cell line Colloids and Surfaces Biointerfaces 91: 212-214

17. Singh. AP, Chaudhary BR, Singh KS \& Dash D (2012). Effect of silver nanoparticles on growth of eukaryotic green algae. Nano-Micro Letter. 4(3): 158165.

18. Andrea R, Dávid K, Nóra I, Csaba V, Imre MB, Zoltán $\mathrm{K}$, Ilona $\mathrm{P}$ \& Mónika $\mathrm{K}$ (2017). Biological activity of greensynthesized silver nanoparticles depends on the applied natural extracts: a comprehensive study. Int J Nanomedicine 12: 871- 883 .

19. Srivastava AA, Kulkarni AP, Harpale PM, Zunjarrao RS (2011). Plant mediated synthesis of silver nanoparticles using a bryophyte Fissidens minutus and its anti- microbial activity, Inter J of Engi Sci and Technol 3(12): 8342-8347.

20. Sathishkumar M, Sneha K, Won S, Cho C, Kim S \& Yun Y (2009). Cinnamon zeylanicum bark extract and powder mediated green synthesis of nanocrystalline silver particles and its bactericidal activity. Colloids Surf B Biointerfaces 73: 332-338

21. Balaji D, Basavaraja S, Deshpande R, Bedre M, Prabhakara B \& Venkataraman A (2009). Extracellular biosynthesis of functionalized silver nanoparticles by strains of Cladosporium cladosporioides fungu. Colloids Surf B 68: 88-92

22. Rastogi L \& Arunachalam J (2017). Sunlight based irradiation strategy for rapid green synthesis of highly stable silver nanoparticles using aqueous garlic (Allium sativum) extract and their antibacterial potential. $J$ of Material and Chem Phy 129(1-2): 558-563.

23. Rajeshkumar S, Kannan C, Annadurai G (2012). Synthesis and characterization of antimicrobial silver nanoparticles using marine brown seaweed Padina tetrastromatica. Drug Invent Today 4: 511513.

24. Shahwan T, Sirrah SA, Nairat M \& Boyaci E (2011). Green synthesis of iron nanoparticles and their application as Fenton-like catalyst for the degradation of aqueous cationic and anionic dyes. Chem Engi J 172(1):258-266.

25. Vigneshwaran N, Ashtaputrea NM, Varadarajana PV, Nachanea RP, Paralikaraand KM \& Balasubramanyaa RH (2007). Biological synthesis of silver nanoparticles using the fungus Aspergillus Flavus. Materials Letters 61(6): 14131418.

26. Jelodarian S, Haghir EA, Khalighi A \& Batooli H (2012). Evaluation of antioxidant activity of Malus domestica fruit extract from Kashan area. Avicenna $J$ of Phytomed 2(3): 139-145. 